\title{
Study of the geometrical and the geotechnical stability of the concrete lozenges channels
}

\author{
Latifa EL BOUANANI ${ }^{1, *}$, Khadija BABA ${ }^{1}$, Lahcen BAHI ${ }^{2}$ and Choukri CHERRADI ${ }^{1}$ \\ ${ }^{1}$ GCE Laboratory, High School of Technology-Sale, Mohammed V University in Rabat-Morocco; \\ ${ }^{1}$ 3GIE Laboratory, Mohamedia Engineering School, Mohammed V University in Rabat-Morocco.
}

\begin{abstract}
Several methods are proposed for improving the slopes stability. We are studying the use of a new technique: concrete lozenges channels. The objective of this technique is to stabilize the slope against water erosion. In addition, it makes it possible to combine both mechanical protection with concrete lozenges channels and protection by plant engineering techniques with plants adapted to the area. The present study is part of the continuation of a parametric study whose purpose was to define the optimal design of concrete lozenges channels. Using the finite element method, the purpose is to study the geotechnical stability of a slope stabilized by said lozenges and to define their constructive arrangements.
\end{abstract}

Key words:Water erosion, concrete lozenges channels stability, finite element method, protection techniques and construction arrangements.

\section{Introduction}

Like several civil engineering works, slopes are subject to the effects of climate change, which cause water erosion and landslides. Water erosion is considered as one of the fracture mechanisms that can compromise the slope stability by causing degradation of the mechanical properties of soils.

The slope stability analysis and the devices study which are used to ensure the stability of slopes requires knowledge of the materials behavior under variable saturation conditions.

The presence of argillaceous materials requires that these particularities be taken into account. As well these types of soil are not homogeneous, and their hydro-mechanical properties depend on the argillaceous phase, which allows them to change the volume of the soil according to its water content[1].

The unsaturated zone is that part of the subsoil that is located between the subsurface and the water table. The water table is an imaginary surface on which the pore pressure is zero[2].In the unsaturated zone, the pores of the soil are filled with water and air, which is different from a saturated zone where the entire porous system is filled with water [3].Darcy's generalized law can describe the flow of water into the soil along the slope. Some hydraulic parameters are required to describe the flow like: infiltration rate, soil hydraulic conductivity, water holding capacity and water table. We can measure these soil hydraulic parameters either in the field or in the laboratory [4]. But, measurement of some soil hydraulic parameters is costly.

Indeed, the concrete lozenges channels are civil engineering works. They are a new technique used for improving the slopes stability. It is a non-continuous mesh mask on the slope, which collects and transports the draining water on the surface of the slope. Consequently, it allows reducing the quantities of soil eroded by surface, and minimizing the water stagnationtime and the infiltration at depth which will influence the shear strength of the slope soil causing significant slippage.

According to RUSLE, this technique directly and mainly influences two factors LS and $\mathrm{P}$ in addition to area exposed to erosion). The slope length factor is a function of the lozenges geometry and especially the length of the diagonal that follows the slope [5].

A numerical model of the slope is defined using Plaxiscode calculations[6], to consider both the mechanical and the hydraulic effects of concrete lozenges channels on the slope stability. This method have the advantage of modeling slopes with very high realism (complex geometry, sequences of loading, presence of materialfor reinforcement, action of water,

*Corresponding author: elbouanani.latifa@gmail.com 
laws for complexes soilbehavior...) and better visualization Deformation site soil[7].

Parametric study shows that after a simulated rainfall, concrete channels can stabilize the shallow soil of up to $9 \mathrm{~m}$ for a slope of $10 \mathrm{~m}$ of depth.

On this, the present study is part of the continuation of a parametric study whose object was to define the optimal design of the lozenges. The purpose of this study is to propose design criteria to help ensure the stability of both concrete lozenges channels and slopes.

\section{Geometrical channels stability}

\subsection{Methods}

\subsubsection{Erosion model}

RUSLE is an erosion model (Wishmeier model) designed to predict the long-time average annual soil loss (A) carried by runoff from specific field slopes in specified cropping and management systems as well as from rangeland. It is also applicable to non-agricultural conditions such as construction sites.

The figure below schematizes the six studied cases (fig. 1):
Soil erosion can be calculated using the Revised Universal Soil Loss Equation such as[8]:

$$
A=R * K * L S * C * P \quad \text { (1) }
$$

$A=$ Predicted soil loss (ton.ha-1.year-1)

$\mathrm{R}=$ Rainfall and runoff factor (MJ .mm/ha.h.year);

$\mathrm{K}=$ Soil erodibility factor (t.h/MJ.mm);

$\mathrm{LS}=$ Slope length and steepness factor (a dimensionless factor);

$\mathrm{C}=$ Crop management factor (a dimensionless factor);

$\mathrm{P}=$ Support practices factor (a dimensionless factor).

\subsubsection{Geometrical stability of the concrete lozenges channels}

The quantification of the slopes soil losses using the Wishmeier model allowed us to discuss the parameters that can influence the choice of lozenges channels geometry like the slope length or the lozenges' diagonals length and the number of lozenges or the area occupied by concrete lozenges channels.

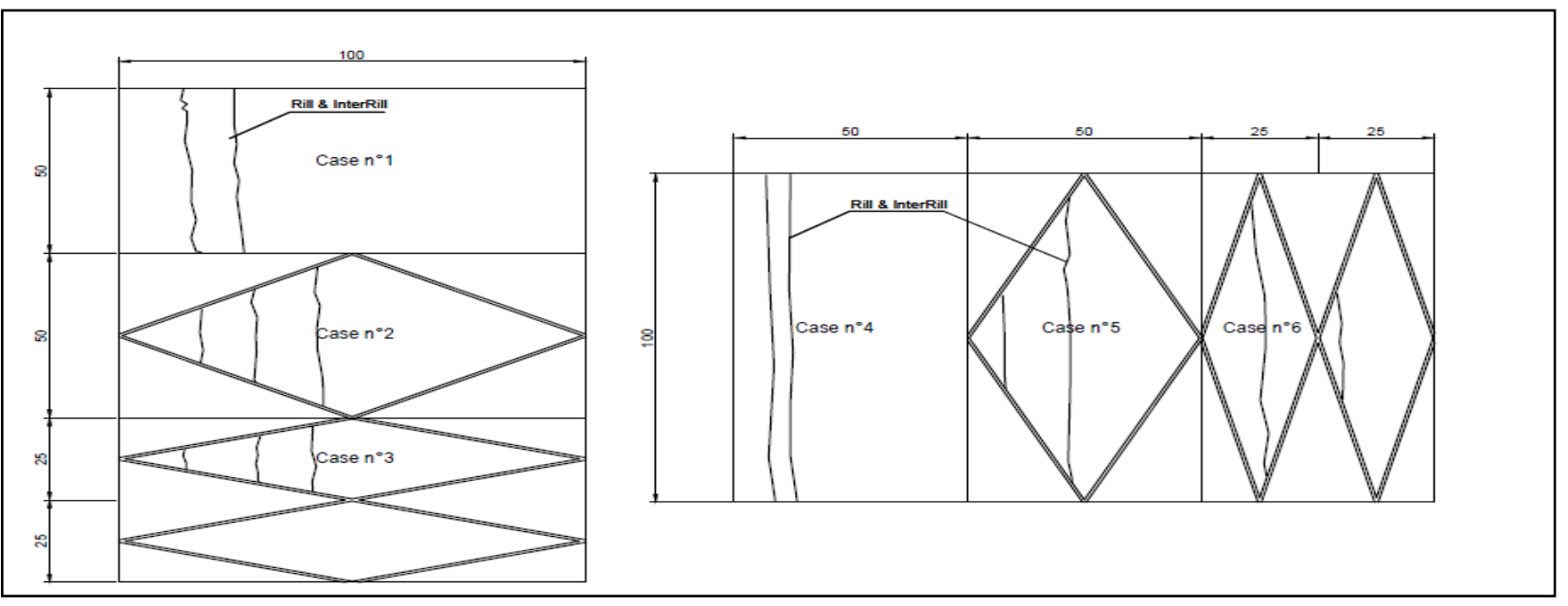

Fig.1. Concrete lozenges channels arrangement

\subsection{Results \& discussions}

\subsubsection{Results}

We are studding the change in the slope length factor per the change in the lozenges diagonal length for the six studied cases.

- $\quad(\mathrm{R})$ and $(\mathrm{K})$ factors are calculated using empirical equations and the zone characteristics [5];

- Slope length and steepness factor (LS) can be defined using the slopes angles in $\%$ and the slopes length in $\mathrm{ft}[4]$;

- The slope is devoid of vegetation cover and support practice $(\mathrm{C}=1$ and $\mathrm{P}=1)$ [9];
- Runoff length $\mathrm{lh}$ is the longest runoff distance in order to reach outlet by a quantity of water (the inclined channel for the case of lozenges-mesh);

- Runoff length equivalent Lr: Runoff length in the concrete lozenges-mesh is simulated at half of the length of lozenge's diagonal.

The table 1contains the data required for the Predicted soil loss calculation both before and after the use of lozenges technique for the six studied cases:

Table 1: Predicted soil loss (A) for the six studied cases

\begin{tabular}{|c|c|c|c|c|c|c|c|}
\hline Lozenges category / Cases & $\mathbf{n}^{\circ} \mathbf{1}$ & $\mathbf{n}^{\circ} \mathbf{2}$ & $\mathbf{n}^{\circ} \mathbf{3}$ & $\mathbf{n}^{\circ} \mathbf{4}$ & $\mathbf{n}^{\circ} \mathbf{5}$ & $\mathbf{n}^{\circ} \mathbf{6}$ & $\mathbf{U n i t}$ \\
\hline Exposed area & 0,5 & 0,48 & 0,47 & 0,5 & 0,48 & 0,47 & $\mathrm{ha}$ \\
\hline
\end{tabular}




\begin{tabular}{|c|c|c|c|c|c|c|c|}
\hline Lozenges category / Cases & $n^{\circ} 1$ & $n^{\circ} 2$ & $n^{\circ} 3$ & $n^{\circ} 4$ & $n^{\circ} 5$ & $n^{\circ} 6$ & Unit \\
\hline LS factor & 7,7 & 4,4 & 3,2 & 13,3 & 7,7 & 7,7 & - \\
\hline Erodibility factor (K) & \multicolumn{6}{|c|}{0,107} & mm.t.h/MJ \\
\hline Erosivity factor (R) & \multicolumn{6}{|c|}{150} & $\begin{array}{c}\text { MJ } \\
. \mathrm{mm} / \text { ha.h.year }\end{array}$ \\
\hline $\begin{array}{l}\text { The slope is devoid of vegetation cover and } \\
\text { support practice }(\mathrm{C}=1 \text { and } \mathrm{P}=1)\end{array}$ & \multicolumn{6}{|c|}{1} & - \\
\hline Predicted soil loss (A) & 61,79 & 34,52 & 24,37 & 107,13 & 59,87 & 58,28 & (ton.year-1) \\
\hline
\end{tabular}

\subsubsection{Discussions}

In discussing the variation between studied cases $\left(\mathrm{n}^{\circ} 1\right.$ to $\mathrm{n}^{\circ} 6$ ), we conclude that(L.elbouanani\& al):

- Concrete lozenges channels reduce the soil loss by $44 \%$ for a single lozenge;

- As the lozenges number goes up, the soil loss become less by $61 \%$ for two lozenges ;

- The reduction in sol loss is linked and conditional on the lozenges geometry: for the same area surrounded by concrete channels we can reduce erosion by $73 \%$ if we choose the adequate geometry.

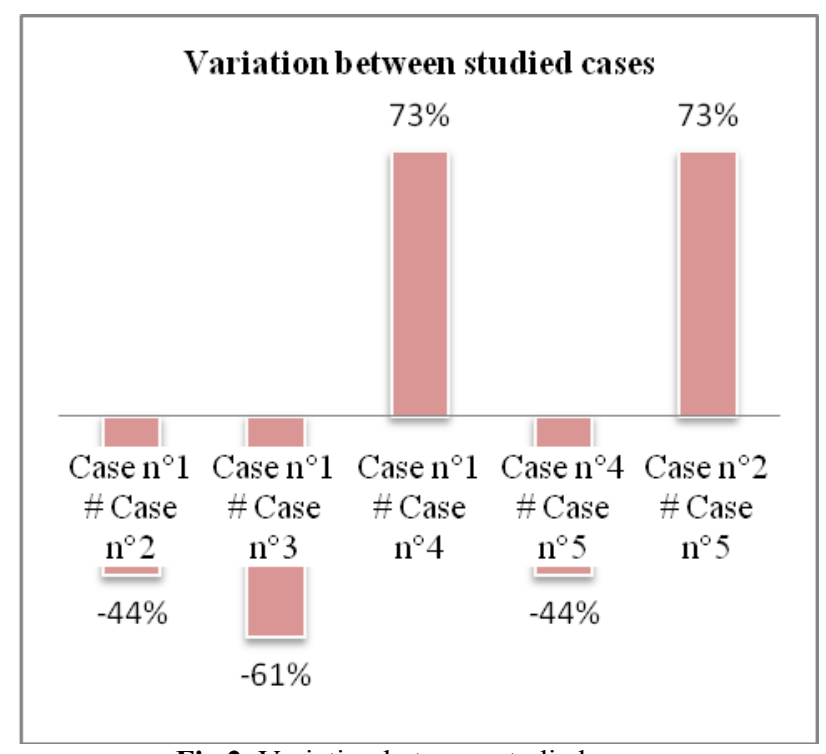

Fig.2. Variation between studied cases

\section{Geotechnical slopes stability}

\subsection{Methods}

\subsubsection{Theoretical framework}

The study of slope instability and degradation of the soil properties requires taking into account the unsaturation conditions of the soil. Unsaturated soil is a three-phase medium. It is composed of a part of solids and pores where two phases coexist, water and air.
To describe the flow of water through a two-dimensional element of unsaturated soil, Darcy's law can be used:

$$
q=k i
$$

Where $\mathrm{q}=$ discharge per unit area, $\mathrm{i}=$ potential gradient, and $\mathrm{k}=$ hydraulic conductivity (permeability).

Darcy's law can be expressed by two partial differential equations:

$$
\Delta q=\frac{\partial \theta_{w}}{\partial t}=-\frac{\partial}{\partial x}\left(k_{x} \frac{\partial h}{\partial x}\right)-\frac{\partial}{\partial y}\left(k_{y} \frac{\partial \hbar}{\partial y}\right)
$$

The hydraulic conductivity of the soil at all points in both the saturated and unsaturated zones is important to describe the flow in them. Van Genuchten[10]and several describe an unsaturated flow model where the amount of water retained in the unsaturated zone of a particular soil depends on the soil water potential $\psi$ (matric suction). The water retention curve is the relationship between the water $\operatorname{content} \theta$, and the soil water potential $\psi$ (matric suction).

\subsubsection{Geotechnical characteristics of the soil}

The slope object of study comprises two different layers whose cumulative thickness is 10 meters. The mechanical and geotechnical characteristics of each layer are given by the following table:

Table2:Mechanical and geotechnical soil characteristics

\begin{tabular}{|c|c|c|c|c|c|c|}
\hline Layer & $\mathbf{Y}_{\text {sat }}$ & $\mathbf{C}^{\prime}$ & $\mathbf{P h i}^{\prime}$ & $\mathbf{\Psi}^{\circ}$ & Erefoed & $\mathbf{V}$ \\
& $\mathbf{K N / \mathbf { m } 2}$ & $\mathbf{K N / \mathbf { m } 3}$ & $\circ$ & $\circ$ & $\mathbf{K N / \mathbf { m } 2}$ & \\
\hline Marl & 18 & 20 & 10 & 0 & 1800 & 0.33 \\
\hline $\begin{array}{c}\text { Yellow } \\
\text { marl }\end{array}$ & 18 & 20 & 10 & 0 & 2100 & 0.30 \\
\hline
\end{tabular}

In fact, the water infiltrated quantities at depth influence the value of the soil saturation degree in each point. As a result, the hydraulic and mechanical soil parametersvary in depth. This variation is taking into account in the PLAXIS software.

At the software level, the part of the slope formed by marl is divided into sub-layers of 1 meter thick (Fig. $3 \& 4)$, the difference between them is at the parameters level, namely:

-General properties : $\Upsilon_{\text {sat }} \& \Upsilon_{\text {unsat }}$

-Permeability : $\mathrm{K}_{\mathrm{x}} \& \mathrm{~K}_{\mathrm{y}}$

-Strenght : C \& $\varphi$ 
The numbering of the soil layers is from top to bottom.

Table 3: The hydraulic and mechanical parameters of soil

\begin{tabular}{|c|c|c|c|c|c|}
\hline & \multicolumn{2}{|c|}{ layers } & \multirow[b]{2}{*}{$\begin{array}{c}\text { Layer } \\
n^{\circ} 3\end{array}$} & \multirow[b]{2}{*}{$\begin{array}{c}\text { Layer } \\
n^{\circ} 4\end{array}$} \\
\hline & & $\begin{array}{c}\text { Layer } \\
\mathrm{n}^{\circ} 1\end{array}$ & $\begin{array}{c}\text { Layer } \\
\mathrm{n}^{\circ} 2\end{array}$ & & \\
\hline \multirow{2}{*}{$\begin{array}{c}\text { General } \\
\text { properties }\end{array}$} & $\begin{array}{c}\Upsilon_{\text {sat }} \\
\mathrm{KN} / \mathrm{m} 3\end{array}$ & 18 & 18 & 18 & 18 \\
\hline & $\begin{array}{l}\mathbf{Y}_{\text {unsat }} \\
\mathrm{KN} / \mathrm{m} 3\end{array}$ & 18 & 17 & 16,5 & 16 \\
\hline \multirow{2}{*}{ Permeability } & $K_{x \text { m/day }}$ & 0,150 & 0,147 & 0,143 & 0,140 \\
\hline & $K_{y}$ m/day & 0,150 & 0,147 & 0,143 & 0,140 \\
\hline \multirow{2}{*}{ Strenght } & $\mathrm{C}_{\mathrm{KN} / \mathrm{m} 2}$ & 5 & 10 & 15 & 17 \\
\hline & $\varphi$ & 10 & 15 & 20 & 20 \\
\hline
\end{tabular}

\subsubsection{Modelling of an unsaturated slope}

For comparative purposes, reduced models with and without protection were studied for a mean rain rates of $30 \mathrm{~mm} / \mathrm{h}$. The objective is to study how these concrete lozenges channels can influence the waters infiltration in depth and their effects on the slope stability.

It is assumed that the instability of the slope is due to the infiltration of water from the soil surface.

Deep water infiltration is a function of the time of precipitationand the rain's intensity.

The boundary conditions are as follows:

- The horizontal displacements along the $X$ axis, and vertical along the $\mathrm{Y}$ axis on the bottom of the massif are all zero.

- The boundary conditions for the flow are deduced, by default, from the general level of the water table by the PLAXIS program.

Figures 4 and 5 respectively represent the mesh and the boundary conditions of the numerical model.

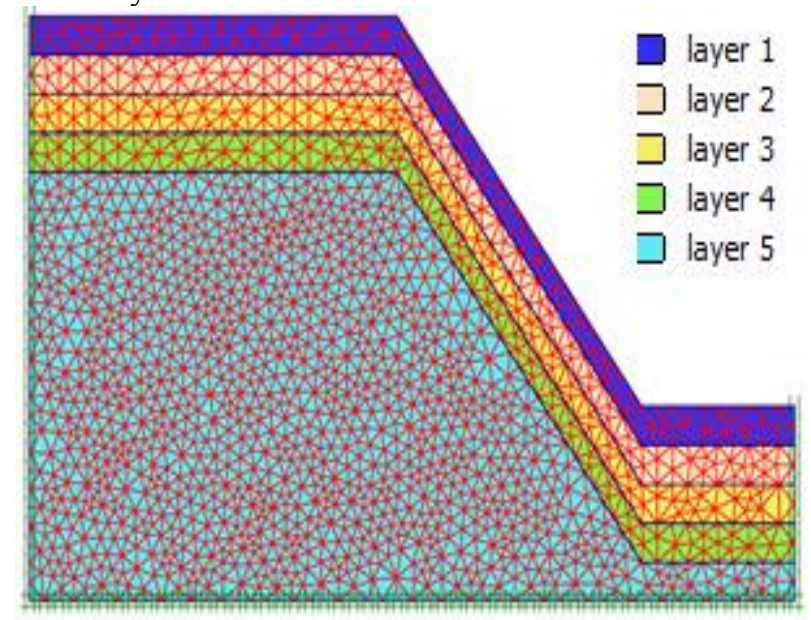

Fig.3. meshof ununsaturated slope

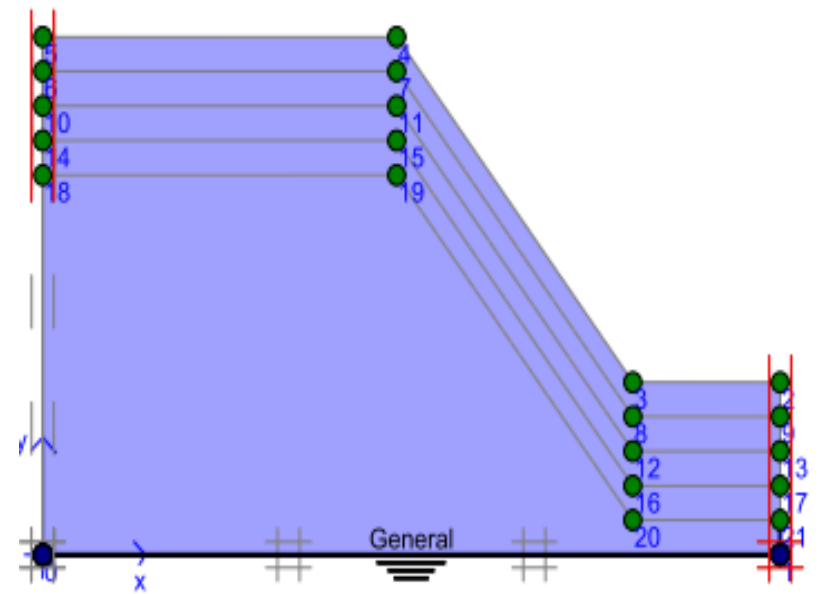

Fig.4. hydraulic boundary conditions ofun unsaturated slope

\subsection{Results \& Discussions}

The security factors are studied for two cases; the first is a slope subject protected by concrete lozenges channels while the second is a non-protected slope.Then the first case is considered like a dry state and the second case a saturated state.

The C \& Phi reduction method according to the Mohr Coulomb criterion is used to calculate the security factor for each case.

\subsubsection{A slope protected by concrete lozenges channels.}

The total displacement for the first case (figure 5)which is a slope protected by concrete lozenges channels is $51,41 \mathrm{~m}$.

The figure 6shows the deformed mesh of the protected slope.

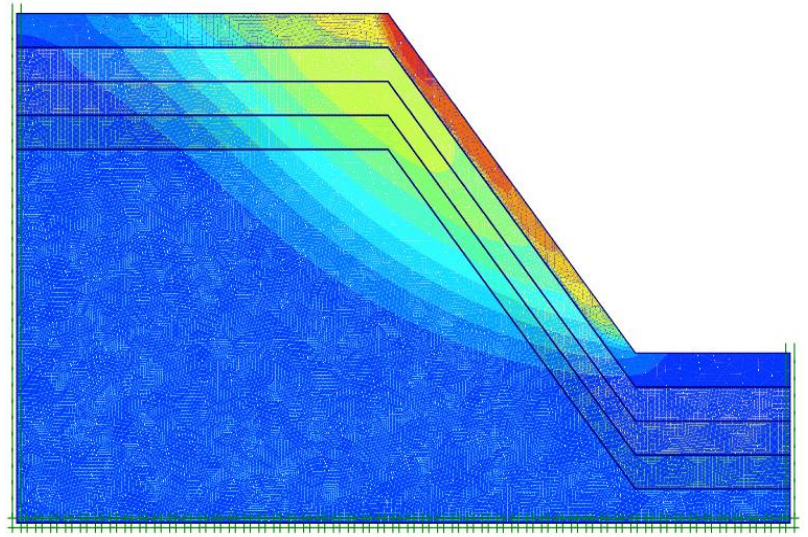

Total displacements $51,41 \mathrm{~m}$

Fig.5. Total displacements of a protected slope 


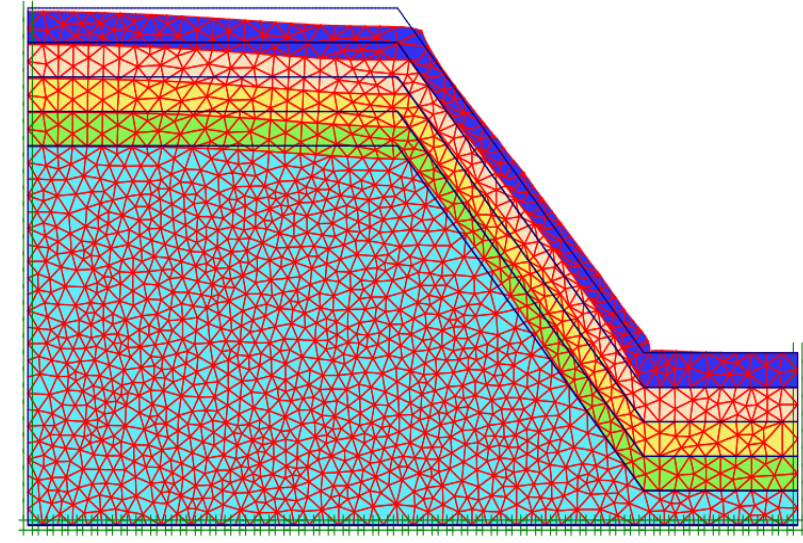

Fig.6. Deformed mesh of a protected slope

\subsubsection{A slope unprotected}

The total displacement for the second case(figure 7) which is a slope unprotected is $148,15 \mathrm{~m}$. The figure 8shows the deformed mesh of the unprotected slope.

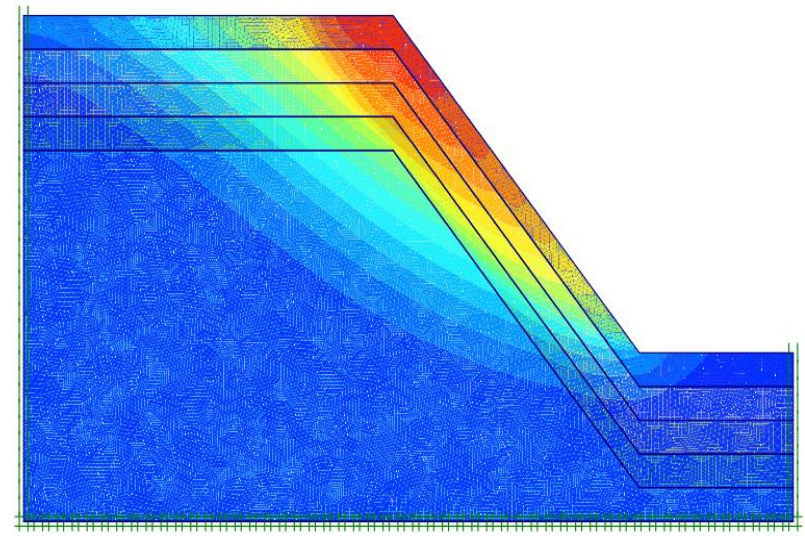

Total displacements $148,15 \mathrm{~m}$

Fig.7. Total displacements of an unprotected slope

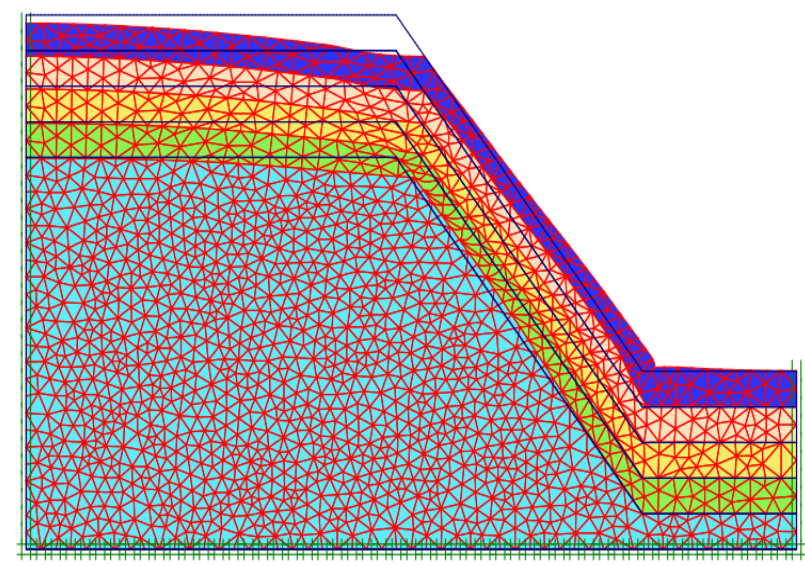

Fig.8. Deformed mesh of an unprotected slope

\subsubsection{Variation of the Security Factor with displacements}

The variation of the Security Factor with displacementfor thesetwo cases is shown by the following figure:

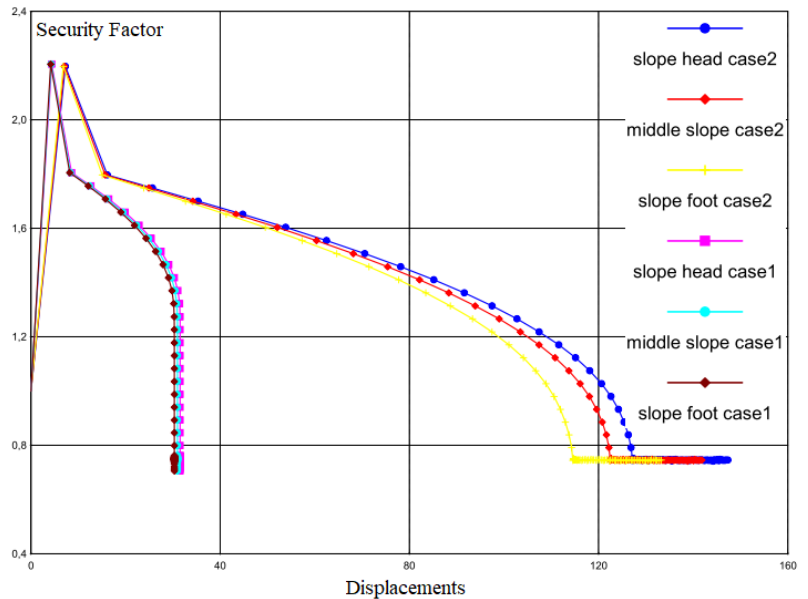

Fig.9. Variation of the security factor with displacement

\subsubsection{Discussion}

The calculation results indicate that total displacements are $51,41 \mathrm{~m}$ for the first case and $148,15 \mathrm{~m}$ for the second case with a security factor less than 1 for the each case.

For the first case (case1), the instability of the slope layer is linked to the saturation of the shallow soil before the runoff. So, concrete lozenges technique can make the amount of soil masse affected, by $72 \%$.

For the second case (case2), the water infiltration continues in deep because of the lack of a device for collecting water and the erosion of the shallow soil layer. We note that the displacement value is important which we can consider that this technique can stabilize the slope against water erosion and can improve the stability of the slope.

Because of the concrete lozenges channels the runoff water is collected and transported to the slope foot before infiltration into the ground, which justifies the difference between the saturation degree at depth between a slope protected by the concrete lozenges channels and a slope without protection.

\section{Recommendations}

Before starting any slopes construction, it is necessary first of all to realize a geotechnical study of the different slope formations. Also the modelling of lozenges must take into account the possibility of leaching the underlying fine materials. On this, to ensure the slope stability the following recommendations are to be followed:

$\checkmark$ The use of geotextile under concrete lozenges channels. It makes it possible to prevent scouring at the base of the structure.

$\checkmark \quad$ The supporting soil of these structures must be fairly stable and compact. It is therefore necessary to provide slope stabilization techniques against water inflow such as: 
-Installation of a drainage channels at the slope head to treat surface and underground water;

- Concrete channels must be routed to a slope foot to ensure continuity of collected and transported water;

- The concrete used for the channels construction must be of good quality and reinforced by reinforcement plies in the form of meshes;

-The concrete lozenges channels are sized according to the water retention capacity along the slope so that all the fallen water is collected by the inclined channels;

-Channels are V-shaped or trapezoidal;

- Channels must be sufficiently anchored in the ground. The anchorage thickness is a function of the nature of the soil and the slope steepness.

\section{Conclusion}

The sizing of inclined channels in the form of lozenges is dependent on the mechanical and hydraulic characteristics of the soils studied under varying saturation conditions. This deep soil saturation is a function of the period and intensity of the precipitation.

Concrete lozenges channels are stabilization works allowing certainly the combination of mechanic structural and vegetal-biological techniques to ensure the stability of slopes against water erosion but requiring, however, a good construction based on geotechnical study and the recommendations cited above. Then this technique can stabilize the slope until $70 \%$.

\section{References}

1.

Bensallam, L. Bahi, H. Ejjaaouani and V. Shakhirev, "A New Shrinkage Curve Model, Applied to Moroccan Clayey Soil," International Journal of Geosciences, Vol. 3 No. 3, pp. $507-514$ (2012). doi: 10.4236/ijg.2012.33053.

2.

LAM, D . G. FREDLUNDA,N D S. L. BARBOU

Transient seepage model for saturated-unsaturated soil systems: a geotechnical engineering approach Can. Geotech. J. 24, 565 -580 (1987).

3. Vincenzo CasulliAnd Paola Zanolli. A Nested Newton-Type Algorithm For Finite Volume Methods Solving Richards' Equation In Mixed Form. Siam J. SCI. COMPUT. c Society for Industrial and Applied Mathematics 32, No. 4, pp. 22552273(2010).

4.

asemAlavi. Estimation Of Soil Hydraulic Parameters To Simulate Water Flux In Volcanic Soils.New Zealand Journal of Forestry Science 31(1): 51-65 (2001)

5. lozenges impact on the slope erodibility. MATEC
Web Conf. 149, 02073. 2nd International Congress on Materials \& Structural Stability (CMSS-2017) (2018).

6. https://doi.org/10.1051/matecconf/201814902073

AXIS, "Finite Element Code for Soil and Rock Analysis," Brinkgreve, et al., Ed., PLAXIS-2D Version 8, Reference Manual, DUT, the Netherlands, (2004). www.plaxis.nl

7.

Baba, L. Bahi, L. Ouadif and A. Akhssas, "SlopeStability Evaluations by LimitEquilibrium and FiniteElementMethodsApplied to a Railway in the Moroccan Rif," Open Journal of Civil Engineering,Vol. 2 No. 1, pp. 27-32 (2012). doi: 10.4236/ojce.2012.21005.

8. Wischmeier, W.H. \& Smith D.D. Prediction rainfall erosion losses, a guide to conservation planning. Science.U.S.Dept. Agriculture. Agric.Handbook537. 60p (1978).

9. A.Chehlafi, A.Kchikachn\& A. Derradji. Protection des talus autoroutiers par arcades bétonnées ou maçonnées. Rock SlopeStability, Marakech (Maroc). 291-300 p (2014).

10 .

$\mathrm{n}$ Genuchten. A closed form for predicting the hydraulic conductivity of unsaturated soils.M.T. SoilsSci. Am. Soc., 44, 892-898, (1980). 